\title{
Coulisses
}

Revue de théâtre

8 | Eté 1993

Varia

\section{Théâtre Universitaire de Glasgow}

\section{(2) OpenEdition}

1 Journals

Édition électronique

URL : http://journals.openedition.org/coulisses/2574

DOI : $10.4000 /$ coulisses. 2574

ISSN : 2546-9460

Éditeur

Presses universitaires de Franche-Comté

\section{Édition imprimée}

Date de publication : 1 juillet 1993

Pagination : 28-29

ISSN : 1150-594X

\section{Référence électronique}

«Théâtre Universitaire de Glasgow », Coulisses [En ligne], 8 | Eté 1993, mis en ligne le 15 mars 2019, consulté le 25 octobre 2019. URL : http://journals.openedition.org/coulisses/2574 ; DOI : 10.4000/ coulisses. 2574

Ce document a été généré automatiquement le 25 octobre 2019

Coulisses 


\section{Théâtre Universitaire de Glasgow}

\section{Le metteur en scène}

\section{Victoria Beattie}

1 Victoria est diplômée de l'Université de Glasgow (études théâtrales et littérature anglaise). Elle a vécu et étudié à Paris à l'Université de Nanterre. Victoria a été choisie par la revue anglaise Theatre Studies pour traduire en anglais les œuvres de Catherine Anne. En 1991, Victoria a écrit et mis en scène Thin-Spun Life, spectacle qui a déjà été présenté à Bordeaux et Bruxelles où il a été reçu avec enthousiasme par la critique. Cette production ira cette année dans plusieurs festivals en Allemagne, Hollande, Slovaquie ainsi qu'au Maroc. 


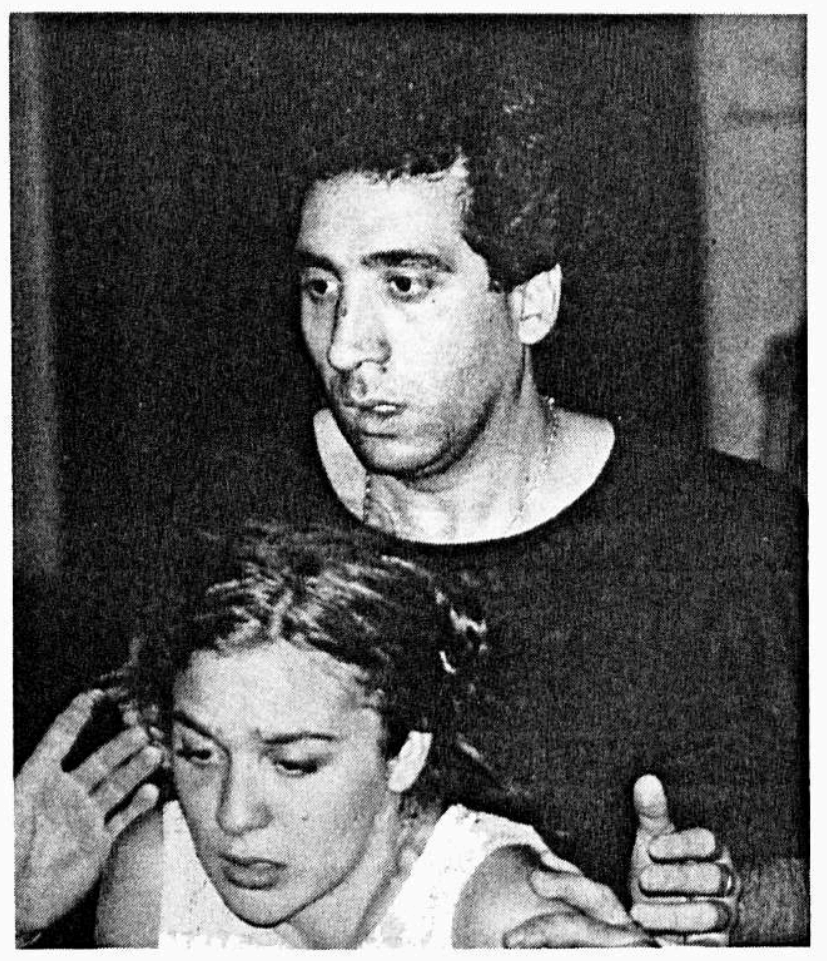

\section{Son point de vue}

2 Comme le dit Ruth Nevo : " c'est une étude de l'au-delà qu'il faut entreprendre » quand on entre dans Cymbeline, pari théâtral unique, qui va générer ses propres règles dans une structure du monde indépendante de la logique. Cymbeline est une pièce d'excès et d'extravagance et nous nous trouvons tout à la fois tragiques et ridicules. Nous cherchons à nous dégager le plus possible du réel en travaillant dans une grande théâtralité. Nous étudions également les différentes formes de communication et de rhétorique que nous pourrions utiliser. Des questions de genre et de libido se posent dans la pièce - il est question de travesti - et pour les exprimer, nous créons des processus de ruptures et de parodies de langage avec des contrepoints de son et de sens. Nous travaillons davantage sur les concepts que sur les personnages. Nous espérons que notre production restera fidèle à l'incroyable complexité de Cymbeline et permettra à l'émotion de se transmettre au public partout où nous irons.

\section{Les étudiants sur scène}

Lisa BALL

Jo CLAYTON

Grant GILLESPIE

Cathy HAUGHTON

Doug HEISE

Hettie JUDAH 
Timothy WEBSTER

Mary WELLS

Théâtre Universitaire de Glasgow

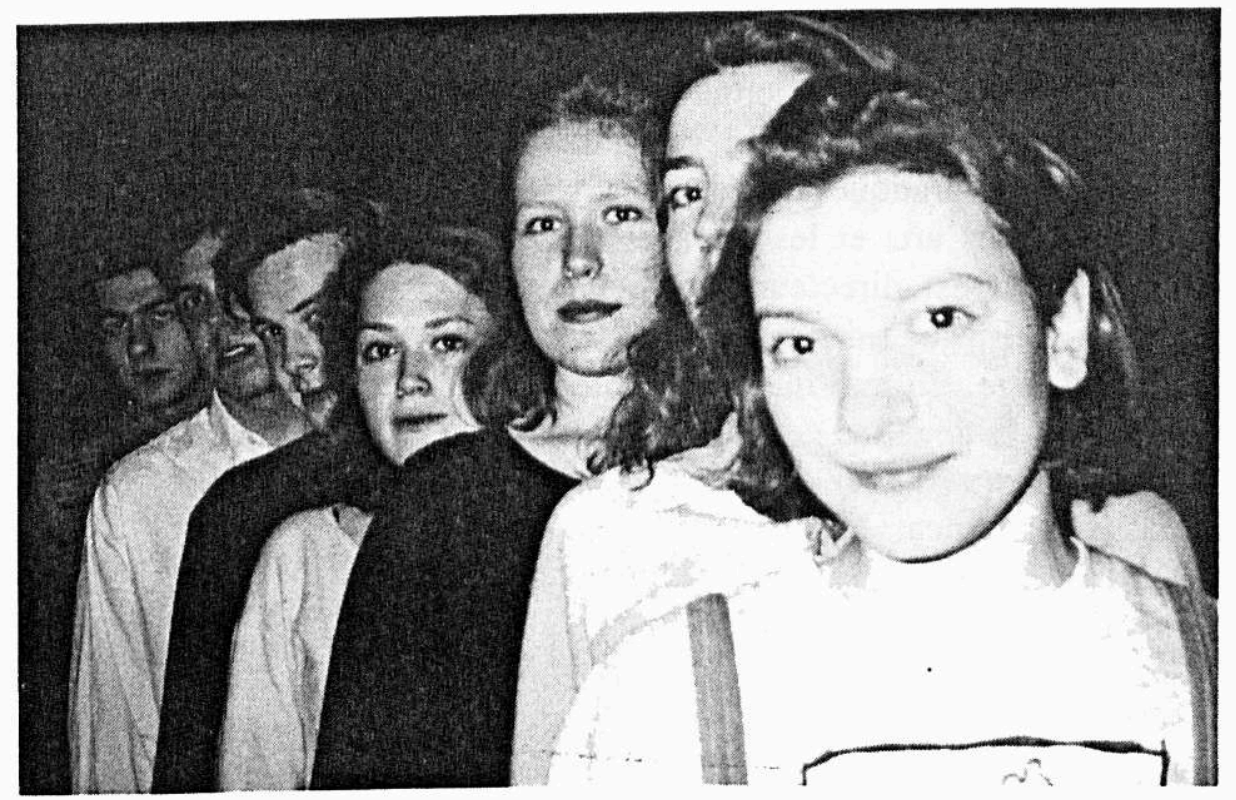

\section{Le T.U.}

Le Département d'Etudes Théâtrales de l'Université de Glasgow a été créé en 1965. Dès le début, ses fondateurs ont affiché une volonté de ne pas séparer les études historiques, esthétiques et théoriques de la pratique théâtrale et ont encouragé les étudiants à monter des spectacles et à se confronter au public. C'est dans des conditions plus que précaires, avec très peu de moyens matériels, que quelques enseignants enthousiastes et des étudiants à la foi chevillée au corps et une vitalité étonnante continuent de travailler. Nous montons régulièrement des spectacles qui sont généralement très bien reçus. Aujourd'hui (le 6 mai 1993), par exemple, un étudiant américain présente sa mise en scène de old Times de Pinter; la semaine dernière, une Hollandaise mettait en scène The Lover; la semaine prochaine se sera le tour d'un Taiwanais avec un spectacle de danse, traditionnelle, suivi d'une pièce de Caryl Churchill montée par un Canadien, ... Avant Pâques, nos étudiants britanniques ont monté quatre ou cinq pièces dont une fut présentée au Festival du Théâtre universitaire de Londres. Hors département, une association d'étudiants monte aussi une dizaine de spectacles par an, dont certains vont en tournée autour de Glasgow et d'autres sont présentés au festival off d'Edinburgh. Récemment, nous avons joué à Liège, Casablanca, Bordeaux et Bruxelles. Sur le chemin de Besançon, nous nous arrêterons à Mainz et cet automne, nous jouerons probablement en Hollande et en Slovaquie. En 1995 nous espérons organiser un festival ici, à Glasgow, pour le plaisir des spectateurs de chez nous et celui de recevoir toutes ces troupes si généreuses qui nous ont invités chez elles. 